\title{
Retention payoff-based cost per day open regression equations: Application in a user-friendly decision support tool for investment analysis of automated estrus detection technologies
}

\author{
K. A. Dolecheck, G. Heersche Jr., and J. M. Bewley ${ }^{1}$ \\ Department of Animal and Food Sciences, University of Kentucky, Lexington 40546
}

\begin{abstract}
Assessing the economic implications of investing in automated estrus detection (AED) technologies can be overwhelming for dairy producers. The objectives of this study were to develop new regression equations for estimating the cost per day open (DO) and to apply the results to create a user-friendly, partial budget, decision support tool for investment analysis of AED technologies. In the resulting decision support tool, the end user can adjust herd-specific inputs regarding general management, current reproductive management strategies, and the proposed AED system. Outputs include expected DO, reproductive cull rate, net present value, and payback period for the proposed AED system. Utility of the decision support tool was demonstrated with an example dairy herd created using data from DairyMetrics (Dairy Records Management Systems, Raleigh, NC), Food and Agricultural Policy Research Institute (Columbia, MO), and published literature. Resulting herd size, rolling herd average milk production, milk price, and feed cost were 323 cows, 10,758 $\mathrm{kg}, \$ 0.41 / \mathrm{kg}$, and $\$ 0.20 / \mathrm{kg}$ of dry matter, respectively. Automated estrus detection technologies with 2 levels of initial system cost (low: $\$ 5,000$ vs. high: $\$ 10,000$ ), tag price (low: $\$ 50$ vs. high: $\$ 100$ ), and estrus detection rate (low: $60 \%$ vs. high: $80 \%$ ) were compared over a 7 -yr investment period. Four scenarios were considered in a demonstration of the investment analysis tool: (1) a herd using 100\% visual observation for estrus detection before adopting 100\% AED, (2) a herd using 100\% visual observation before adopting $75 \%$ AED and $25 \%$ visual observation, (3) a herd using 100\% timed artificial insemination (TAI) before adopting 100\% AED, and (4) a herd using 100\% TAI before adopting $75 \%$ AED and 25\% TAI. Net present value in scenarios 1 and 2 was always positive, indicating a positive investment
\end{abstract}

Received September 7, 2015.

Accepted August 3, 2016.

${ }^{1}$ Corresponding author: jbewley@uky.edu situation. Net present value in scenarios 3 and 4 was always positive in combinations using a $\$ 50$ tag price, and in scenario 4 , the $\$ 5,000, \$ 100$, and $80 \%$ combination. Overall, the payback period ranged from $1.6 \mathrm{yr}$ to greater than $10 \mathrm{yr}$. Investment analysis demonstration results were highly dependent on assumptions, especially AED system initial investment and labor costs. Dairy producers can use herd-specific inputs with the cost per day open regression equations and the decision support tool to estimate individual herd results.

Key words: cost of days open, estrus detection, precision dairy farming, investment analysis, decision support

\section{INTRODUCTION}

Reproductive performance is one of the largest factors affecting dairy farm profitability because of its direct relationship to milk production, replacement animal availability, genetic progress, and culling (Britt, 1985; Plaizier et al., 1997; Olynk and Wolf, 2008). A variety of reproductive management methods are used on dairy farms throughout the world, including bull breeding, visual observation for estrus (VO), visual detection aids (e.g., tail paint, heatmount detectors), timed artificial insemination (TAI), and automated estrus detection (AED). Reproductive management method profitability differs depending on associated costs (e.g., labor, tail paint, hormones, AED technologies) and resulting estrus detection rate (EDR) and conception rate (CR; Holmann et al., 1987; Olynk and Wolf, 2009). Additional reproductive management expenses include those linked to semen purchases, insemination costs, and pregnancy diagnosis.

Multiple models dedicated to calculating economic differences between reproductive management methods exist (Giordano et al., 2011, 2012; Galvão et al., 2013). Modeling is valuable for determining economic differences associated with changes in management (such as reproductive programs) because it allows comparisons between different levels of performance without the 
complexity of on-farm testing. However, application of economic models to investment analysis of AED technologies is rare. Dairy producers' concerns over large AED investment costs and uncertainty in AED system payback have been identified in multiple surveys (Russell and Bewley, 2013; Borchers and Bewley, 2015), emphasizing a need for these types of decision support tools.

Some economic analysis of AED technologies has begun. Rutten et al. (2014) estimated changes in calving interval, milk production, feed requirements, sellable calves, insemination number, inseminations per calf, culling occurrence, and labor hours when switching from visual estrus detection to activity meters on an average Dutch dairy using a stochastic simulation approach. The advantage of stochastic simulation is that a large variety of scenarios can be tested to improve accuracy of expected outcome estimates. The disadvantage of stochastic simulation is that the complexity and software requirements limit the number of users that can benefit from individual farm use of the tool. Fricke et al. (2014) estimated the net present value (NPV) of using AED at first insemination on a 1,000-cow commercial Wisconsin dairy using a previously developed Markov-chain simulation model (Giordano et al., 2012). Although this approach may reduce the accuracy of results compared with stochastic simulation in some scenarios, it presents more opportunities as a user-friendly decision support tool. Ideally, decision-making models should be as simple as possible, while maintaining as much accuracy as possible (Groenendaal et al., 2004).

Because of the pros and cons associated with each modeling approach, our research included a combination of multiple modeling techniques. First, a stochastic simulation model was used to collect data for building herd and parity-specific cost per day open (DO) equations. Such equations could be useful for estimating the value associated with changes in reproductive performance. Second, a deterministic, partial budget model was used to apply the new cost per DO equations in the creation of a user-friendly, decision support tool for investment analysis of AED technologies. A demonstration of the tool was conducted using data representative of a mid-sized US dairy herd.

\section{MATERIALS AND METHODS}

\section{Objective 1}

Data sets including both herd-specific financial and production parameters are limited. Therefore, data sets were created using the whole-farm, stochastic simula- tion model previously described by Bewley et al. (2010). In short, the model simulates a dairy herd over a 10-yr period with daily time steps. Revenues associated with milk yield and calf production and costs associated with feeding, breeding, veterinary needs, and mortality are each calculated on a daily basis. Ten thousand iterations of the model were simulated for each parity $(1-5)$ to collect data used to build the parity-specific cost per DO regression equations.

Stochastic Variable Estimates. The stochastic nature of the model allowed key variables assumed to influence cost per DO to change with each iteration of the model. The goal was for each of the 10,000 iterations to represent a unique farm situation. The herd-level variables defined as stochastic for this model included CR, HDR, voluntary waiting period (VWP), age at first calving, rolling herd average milk production, semen cost, replacement price, mature cow live weight, cull cow price, DIM to assign an open cow as a reproductive cull, feed price, milk price, and yearly veterinarian costs per cow. The values of the stochastic variables in each iteration were determined by randomly drawing a value from a predefined probability distribution via the @Risk add-on (Palisade Corporation, Ithaca, NY) for Excel 2013 (Microsoft, Redmond, WA). All stochastic variables used either a PERT distribution (defined by a minimum, maximum, and mode) or a PERTAlt distribution (defined by the expected 2.5th percentile, "most likely" value, and 97.5th percentile). Values used to define probability distributions were selected based on industry data from DairyMetrics (Dairy Records Management Systems, Raleigh, NC), the Food and Agricultural Policy Research Institute (Columbia, MO), and published literature and were adjusted to represent feasible and realistic scenarios as determined by the authors. Table 1 includes the range of stochastically drawn values for each variable after outlier removal (see Regression Equations section for description of outlier removal).

Cost per DO Estimates. For each iteration of the simulation, the daily revenues and costs calculated by the whole-farm model were used to calculating the retention payoff (RPO) value of the average cow in the simulated herd on each day of each parity. The RPO value represents the future profitability of a cow compared with her immediate replacement (Groenendaal et al., 2004). Groenendaal et al. (2004) previously used $\mathrm{RPO}$ values to estimate the cost of DO on a monthly basis. In our model, the calculation of cost per DO was adapted to be identical to that of Groenendaal et al. (2004), except that it used daily RPO values, therefore allowing daily cost per DO estimates. 
Table 1. Assumptions necessary to conduct an investment analysis demonstration of automated estrus detection technologies ${ }^{1}$

\begin{tabular}{|c|c|c|c|}
\hline Input & $\begin{array}{l}\text { Range in stochastic } \\
\text { variable output }\end{array}$ & $\begin{array}{l}\text { Assumption used } \\
\text { in demonstration }\end{array}$ & $\begin{array}{l}\text { Investment analysis demonstration } \\
\text { assumption source }\end{array}$ \\
\hline Age at first calving (mo) & $19.5-31.0$ & 25.6 & DairyMetrics (from 2015) \\
\hline Conception rate $(\%)$ & $16-55$ & 36.8 & DairyMetrics (from 2015) \\
\hline DIM do not breed ${ }^{5}$ (d) & $202-398$ & 300 & Bewley et al., 2010 \\
\hline Discount rate $(\%)$ & $\mathrm{NA}^{6}$ & 8.0 & Hyde and Engel, 2002 \\
\hline Feed $\operatorname{cost}^{4}(\$ / \mathrm{kg}$ of DM $)$ & $0.16-0.24$ & 0.20 & FAPRI (from 2015) \\
\hline Milking herd size (cows) & NA & 323 & DairyMetrics (from 2015) \\
\hline Percent of herd in 1st parity & NA & 36.1 & Dhuyvetter et al., 2007 \\
\hline Percent of herd in 2 nd parity & NA & 26.0 & Dhuyvetter et al., 2007 \\
\hline Percent of herd in 3rd parity & NA & 17.7 & Dhuyvetter et al., 2007 \\
\hline Percent of herd in 4 th parity & NA & 11.0 & Dhuyvetter et al., 2007 \\
\hline Percent of herd $\geq 5$ th parity & NA & 9.2 & Dhuyvetter et al., 2007 \\
\hline Voluntary waiting period (DIM) & $45-98$ & 58.6 & DairyMetrics (from 2015) \\
\hline
\end{tabular}

\footnotetext{
${ }^{1}$ Stochastic variables used to create cost per day open regression equations include the range in stochastic values over all parities and all iterations following removal of the top and bottom $1 \%$ (based on cost per day open) in each parity.

${ }^{2}$ DairyMetrics information was collected in December 2015 from Dairy Records Management Systems (Raleigh, NC). Values gathered from DairyMetrics used the limitations of only Holstein herds with more than 100 cows and 21-d estrus detection rate between 10 and $70 \%$.

${ }^{3}$ FAPRI data (from 2015) were from the Food and Agricultural Policy Research Institute (Columbia, MO).

${ }^{4}$ Ten-year predicted mean (2015-2024).

${ }^{5}$ Days in milk dictating an open cow as a reproductive cull.

${ }^{6} \mathrm{NA}$ indicates variables that were deterministic (not stochastic) in the simulation model.

${ }^{7}$ Rolling herd average.
}

In short, the cost per DO was calculated by comparing the RPO of the average cow in the herd under 2 scenarios: a base scenario and a test scenario (Groenendaal et al., 2004):

$$
\mathrm{CDO}_{i}=\frac{(\text { RPOTest }- \text { RPOBase })}{\text { DIMConcBase }- \text { DIMConcTest }},
$$

where $\mathrm{CDO}=$ cost per DO in parity $i(\$)$ when DIM at conception $=$ DIMConcTest, RPOTest $=$ RPO of the average cow on the first day of parity $i$ in the test scenario, $\mathrm{RPOBase}=\mathrm{RPO}$ of the average cow on the first day of parity $i$ in the base scenario, DIMConcBase $=$ DIM at conception in parity $i$ for the base scenario, and DIMConcTest $=$ DIM at conception in parity $i$ for the test scenario.

The only difference between the base and test scenarios was how DIM at conception was defined in parity $i$, which in turn influenced the RPO in each scenario. Base scenario DIM at conception in parity $i$ was calculated using the stochastically selected HDR and CR. Test scenario DIM at conception in parity $i$ was determined stochastically from its own probability distribution ranging from a minimum of the stochastically selected VWP to a maximum of the stochastically selected DIM to assign an open cow as a reproductive cull. In both the base and test scenarios, DIM at conception for all parities not parity $i$ was identical to the base scenario DIM at conception. To restate, this method resulted in DIM at conception being identical in all parities of both scenarios (base and test) except parity $i$ in the test scenario.

Using this method, a unique DO comparison was made during each iteration of each lactation. For example, in iteration 1 of lactation 5 a cow conceiving at 233 DIM was compared with a cow conceiving at 124 DIM. In iteration 2 of lactation 5, a cow conceiving at 363 DIM was compared with a cow conceiving at 132 DIM. This continued for all 10,000 iterations, resulting in 10,000 unique comparisons.

Regression Equations. Building the cost of DO regression equations involved modeling the predicted cost per DO from the simulation model against the collected stochastic variables in each iteration, including the stochastically selected DIM at conception for 
the test scenario. The 10,000 data points from each parity-specific simulation were handled separately to create the parity-specific CDO equations. However, the steps for building each parity-specific equation were identical. First, data were cleaned by removing the top and bottom $1 \%$ of iterations based on the average cost of DO. This step removed extreme scenarios considered outliers. Next, the REG procedure of SAS (version 9.3, SAS Institute, Inc., Cary, NC) was used to plot residuals for all stochastic variables. Residual plots were examined for normality, and abnormal plots were used to identify variables in need of transformation. Logarithmic transformations were applied to VWP and yearly veterinarian costs per cow variables in all 5 parity-specific data sets. Additionally, the DIM at conception for the test scenario variable was squared in all 5 parity-specific data sets.

The transformed data sets were analyzed using the GLMSELECT procedure of SAS. Each parity-specific model statement included all 14 stochastically simulated variables, the transformed variables (VWP, yearly veterinarian costs per cow, and DO), and 2-way interactions between the transformed DIM at conception for the test scenario variable and all other covariates. Main effects were forced into the model, regardless of significance, using the include statement of the GLMSELECT procedure. Interactions remained in each model if significant at $P<0.05$.

Finally, parameter estimates from the parity-specific GLMSELECT models were used to create the parityspecific cost per DO regression equations. These equations estimate the cost of a single DO at a specific point in lactation. All parity-specific cost per DO equations were imbedded into the AED decision support tool (described in Objective 2) so that the total cost of DO could be estimated for both pre- and post-AED investment scenarios.

\section{Objective 2}

The second objective of this study was to create and demonstrate a user-friendly, decision support tool for investment analysis of AED technologies. A deterministic, partial budget model to investigate the economics of transitioning to AED from an alternative reproductive management method was developed using Excel 2013. The model calculated costs associated with 4 specific aspects of reproductive management at the herd level: (1) extended DO, (2) semen use, (3) pregnancy diagnosis, and (4) reproductive management method. For the first 3 categories, costs were calculated for 2 groups of cows: (1) those becoming pregnant within a year and (2) reproductive culls within a year. All 4 categories of costs were calculated for both pre- and post-AED investment scenarios. Differences in total costs between pre- and post-AED investment were used to conduct investment analysis, including NPV and payback period.

Extended Days Open Costs. To find costs associated with extended DO, the mean expected number of DO for pregnant cows was first calculated using an equation from Pecsok et al. (1994):

$$
\begin{aligned}
& \mathrm{DO}=\left(\begin{array}{l}
(\mathrm{VWP}+10.5)+21 \\
\left.\times\left\{\left[\frac{(1-\mathrm{PR})-(1-\mathrm{PR})^{\mathrm{N}}}{\mathrm{PR}}\right]-\mathrm{N}-1\right\} \times(1-\mathrm{PR})^{\mathrm{N}}\right)
\end{array}\right. \\
& +\left[(\mathrm{DNB}-\mathrm{VWP}-21) \times(1-\mathrm{PR})^{\mathrm{N}}\right],
\end{aligned}
$$

where $\mathrm{DO}=$ expected mean days open for pregnant cows, $\mathrm{VWP}=$ voluntary waiting period, $\mathrm{PR}=$ mean 21-d pregnancy rate as calculated by the multiplication of 21-d EDR and CR, $\mathrm{N}=$ maximum number of eligible breeding cycles for the average cow (determined by subtracting the VWP from DNB and dividing by the length of either the estrus cycle or breeding interval in scenarios where TAI was used), and DNB = the DIM to stop breeding a cow if she has not yet become pregnant (i.e., reproductive cull criteria).

Mean calving interval was then calculated as the sum of gestation length $(280 \mathrm{~d})$ and expected DO for pregnant cows (Meadows et al., 2005). The number of cows eligible for breeding each year was subsequently determined, based on the number of cows calving each year:

$$
\mathrm{CEB}=(\mathrm{HS}) \times \frac{365.25}{(\mathrm{CI} \times 30.42)},
$$

where $\mathrm{CEB}=$ mean number of cows eligible for breeding per year, $\mathrm{HS}=$ mean milking herd size, and $\mathrm{CI}=$ mean calving interval.

Given the number of cows eligible for breeding per year, the expected number of reproductive culls per year was calculated using an equation from Pecsok et al. (1994):

$$
\text { RCull }=\mathrm{CEB} \times(1-\mathrm{PR}) \frac{(\mathrm{DNB}-\mathrm{VWP}-10.5)}{21},
$$

where $\mathrm{RCull}=$ mean number of reproductive culls per year, $\mathrm{CEB}=$ mean number of cows eligible for breeding per year, $\mathrm{PR}=$ mean 21-d pregnancy rate, $\mathrm{DNB}=$ the DIM to stop breeding a cow if she has not yet become pregnant, and VWP = voluntary waiting period. 
The total cost of DO per cow was calculated separately for the pregnant vs. reproductive cull cows, but both used the parity-specific regression equations for cost per DO. As mentioned earlier, these equations calculated the cost of one DO at a specific point in lactation. Therefore, the total cost of DO per pregnant cow in parity $i$ was the sum of the cost per DO of every day between the VWP and the expected days open for pregnant cows. The total cost of DO per reproductive cull cow in parity $i$ was the sum of the cost per DO of every day between the VWP and the DIM designated to stop breeding a cow if she has not yet become pregnant (DNB).

This allowed for the calculation of total yearly economic losses resulting from DO for both pregnant and reproductive cull cows in each parity:

$$
\begin{aligned}
& \operatorname{PregTYCDO}_{i}=\left[(\mathrm{CEB}-\mathrm{RCull}) \times \text { Parity }_{i}\right] \times \operatorname{PregTCDO}_{i}, \\
& \text { CullTYCDO }_{i}=\left({\text { RCull } \times \text { Parity }_{i}}\right) \times \text { CullTCDO }_{i},
\end{aligned}
$$

where PregTYCDO = total yearly cost of days open in parity $i$ for all pregnant cows, CullTYCDO = total yearly cost of days open in parity $i$ for all reproductive cull cows, $\mathrm{CEB}=$ mean number of cows eligible for breeding in the current year, $\mathrm{RCull}=$ mean number of reproductive culls in the current year, Parity $_{i}=$ percentage of cows in parity $i$, PregTCDO ${ }_{i}=$ total cost of DO per pregnant cow in parity $i$, and $\mathrm{CullTCDO}_{i}=$ total cost of DO per reproductive cull in parity $i$.

Finally, the total losses due to DO each year was the sum of total yearly DO costs associated with pregnant cows in each parity and the totally yearly DO costs associated with reproductive culls in each parity.

Semen Costs. The total number of inseminations in a year was calculated as the sum of inseminations in pregnant cows and inseminations in reproductive cull cows. The number of inseminations in pregnant cows was found by multiplying the mean number of pregnant cows per year (cows eligible for breeding minus reproductive culls) by the estimated mean services per conception, calculated as

$$
\mathrm{SPC}=\frac{(\mathrm{DO}-\mathrm{DIM} 1)}{\mathrm{BI}},
$$

where $\mathrm{SPC}=$ mean services per conception, $\mathrm{DO}=$ mean days open for pregnant cows, DIM1 = mean DIM at first service, and $\mathrm{BI}=$ mean breeding interval.

For reproductive cull cows, inseminations per cow was calculated by replacing DO with the DIM designated to stop breeding a cow if she has not yet become pregnant.
In scenarios using TAI, breeding interval (the length of time between inseminations) was defined according to the chosen TAI protocol, and DIM at first service was assumed the last day of the VWP. For scenarios in which TAI was not used, BI was calculated as the average length of the estrus cycle $(21 \mathrm{~d})$ divided by the 21-d EDR. Mean DIM at first service was calculated using the equation from Pecsok et al. (1994):

$$
\mathrm{DIM} 1=\left(\frac{21}{\mathrm{EDR}}\right)+\mathrm{VWP}-\mathrm{N},
$$

where DIM1 = mean DIM at first service, EDR = mean 21-d estrus detection rate, VWP $=$ voluntary waiting period, and $\mathrm{N}=$ maximum number of eligible breeding cycles for the average cow (determined by subtracting the VWP from DNB and dividing by the length of either the estrus cycle or breeding interval in scenarios in which TAI was used).

Yearly semen costs were calculated by multiplying the total number of inseminations in a year (in both pregnant and reproductive cull cows) by mean semen cost per unit.

Pregnancy Diagnosis Costs. The mean number of pregnancy diagnosis events in a year for both pregnant and reproductive cull cows was calculated using 2 assumptions: (1) pregnancy diagnosis occurred following all inseminations resulting in conception and (2) pregnancy diagnosis occurred after all failed inseminations (i.e., those not leading to pregnancy) in TAI scenarios and at a rate equal to 1 minus 21-d EDR in non-TAI scenarios. The second assumption accounts for a pregnancy diagnosis only occurring if the cow has not already been rebred. Mean yearly pregnancy diagnosis costs were calculated by multiplying the mean number of pregnancy diagnosis events in a year (in both pregnant and reproductive cull cows) by the mean pregnancy diagnosis cost.

Pre-AED Reproductive Management Costs. The pre-AED investment reproductive management method could be selected from the following list: bull breeding, technician service, VO, visual detection aids, or TAI. How reproductive management costs were calculated depended on which option was selected. When bull breeding was selected, the annual cost of maintaining a bull was considered the only source of yearly reproductive management costs. When a technician service was selected, cost per cow breeding was multiplied by the mean number of inseminations per year (in both pregnant and reproductive cull cows) to determine yearly variable reproductive management costs. When VO was selected, mean weekly hours of 
labor required for visual observation and hourly cost of labor were multiplied together to determine mean weekly labor costs. Mean weekly labor costs were then translated to yearly variable reproductive management costs by assuming every week was identical. When visual detection aid was selected, labor costs associated with reproductive management were calculated similarly to VO scenarios. Cost per visual detection aid was multiplied by the mean number of inseminations per year (in both pregnant and reproductive cull cows) and added to yearly labor costs to determine total yearly variable reproductive management costs in visual detection aid scenarios. When TAI was selected, labor costs associated with reproductive management were calculated similarly to VO scenarios. Hormone costs were calculated by dividing the cost of a bottle of hormone by the number of doses of hormone per bottle, and then multiplying the resulting cost per injection by the number of injections of that hormone used per insemination and the mean number of inseminations per year (in both pregnant and reproductive cull cows) to determine total yearly hormone costs. Hormone costs were calculated separately for both $\mathrm{GnRH}$ and $\mathrm{PGF}_{2 \alpha}$, allowing for a variety of TAI protocols to be tested. Total yearly hormone costs were added to labor costs associated with TAI to calculate total yearly variable reproductive management costs in TAI scenarios. When TAI was selected, breeding interval was also required as an input for services per conception calculations.

Pre-AED investment variable reproductive management costs could be either eliminated (if planning to use AED exclusively for reproductive management post-AED investment) or reduced by a specific percentage (if planning to use a combination of reproductive management methods post-AED investment). For example, if the pre-AED investment method was associated with a variable cost of $\$ 10.00$ per cow per year and a dairy producer decided to keep using this method $25 \%$ of the time post-AED investment, variable costs were reduced to $\$ 2.50$ per cow per year, plus costs per cow associated with the AED system. Additionally, if the selection was made to continue using a portion of the pre-AED investment reproductive management method, post-AED investment EDR was calculated as a weighted mean of the pre- and post-AED investment EDR. For example, if pre-AED investment reproductive management method EDR was $60 \%$ and was still used $25 \%$ of the time post-AED investment, with an AED EDR of $80 \%$, post-AED investment EDR would be $75 \%$. Because improved insemination timing relative to ovulation is possible when using AED (Stevenson et al., 2014), post-AED investment CR could be calculated in a similar manner. However, if increasing CR
post-AED investment depends on increasing breeding times each day then a user would need to account for those increased labor costs separately.

AED Reproductive Management Costs. Total investment cost of the AED system was calculated as

$$
\mathrm{TIC}=\mathrm{II}+[\mathrm{MCOST} \times(\mathrm{MCOW} \times \mathrm{HS})],
$$

where TIC $=$ total investment cost, II = initial investment cost, MCOST = individual tag price of the AED technology, $\mathrm{MCOW}=$ the percentage of the herd receiving an AED tag, and HS = mean herd size.

In addition to investment costs, variable costs accounted for in the AED scenario included labor cost, the cost to replace lost or broken tags, and the maintenance cost charged by the AED manufacturer. The mean weekly hours of labor required for AED management (i.e., to check and follow up on AED system reports and time associated with breeding multiple times per day, if applicable) was multiplied by the hourly cost of labor to determine mean weekly labor costs. Mean weekly labor costs were then translated to yearly labor costs by assuming every week was identical. The percentage of tags to replace each year was multiplied by the number of tags originally purchased (percentage of herd to receive an AED tag multiplied by mean herd size) to calculate yearly costs associated with replacing lost or broken tags. Yearly maintenance cost was a direct input into the model; no intermediate calculations were necessary.

Investment Analysis. Differences between preand post-AED investment total yearly costs associated with extended DO, semen purchases, pregnancy diagnosis, and reproductive management method were used to calculate yearly change in cash flow. Cash flow was used in the equation published by Boehlje and Ehmke (2005) to calculate NPV of the AED system over a specific investment period, assuming no terminal value at the conclusion:

$$
\mathrm{NPV}=\sum_{n=0}^{n}\left(\frac{\mathrm{FLOW}}{(1+\mathrm{DR})^{n}}\right)-\mathrm{TIC},
$$

where NPV $=$ the net present value of the AED system over the investment period, $n=$ the year of investment, FLOW = the change in cash flow for each year $n$, DR $=$ the discount rate, and $\mathrm{TIC}=$ the total investment cost of the AED system (initial system cost plus total tag costs).

Cash flow was also used to calculate payback period in years for the AED investment using the following equation: 


$$
\mathrm{PP}=\frac{L_{n}}{\left(\mathrm{CC}_{n} / \mathrm{CA}_{n+1}\right)},
$$

where $\mathrm{PP}=$ payback period, $L_{n}=$ the last year $(n)$ of negative cumulative cash flow, $\mathrm{CC}_{n}=$ the absolute value of cumulative cash flow in year $n$, and $\mathrm{CA}_{n+1}=$ the actual cash flow in the year after $n$.

Interface. In addition to the spreadsheet version, the model was also developed into a user-friendly, decision support tool using Xcelsius 4.0 (SAP BusinessObjects, Newtown Square, PA). The end user can adjust herd specific inputs regarding general management, current reproductive management strategies, and the proposed AED system. Reproductive performance outputs for the user included current and estimated new (postAED investment) mean DO and estimated change in reproductive cull rate, calculated as the percentage of cows reaching DNB status in one year. Estimated investment analysis results were also included as outputs in the form of NPV and payback period. The decision support tool is available online at https://afs.ca.uky. edu/dairy/decision-tools/HeatDetectionTech.

\section{Investment Analysis Demonstration}

To demonstrate model utility, a 7-yr investment analysis demonstration was conducted. Example dairy herd input assumptions were gathered from DairyMetrics (Dairy Records Management Systems), Food and Agricultural Policy Research Institute (FAPRI; Columbia, $\mathrm{MO}$ ), and published literature. Values gathered from DairyMetrics used the limitations of only Holstein herds with more than 100 cows and a 21-d EDR between 10 and $70 \%$, to attempt elimination of herds misreporting EDR. Yearly predicted means for milk price, feed cost, and cull cow value were collected from FAPRI for a 10-yr period (2015-2024) and averaged to reduce the effects of high or low prices at one specific time point. Yearly predicted means for replacement cost are not provided by FAPRI and were therefore estimated using a regression equation developed by Bewley et al. (2010) for the same 10-yr period (2015-2024) before averaging for use in the model. Resulting herd size, rolling herd average milk production, milk price, and feed cost were 323 cows, $10,758 \mathrm{~kg}, \$ 0.41 / \mathrm{kg}$, and $\$ 0.20 / \mathrm{kg}$ of DM, respectively. The remaining herd assumptions used in the investment demonstration are shown in Table 1.

Four scenarios were considered in the investment analysis demonstration: (1) a herd using 100\% VO for estrus detection before adopting 100\% AED, (2) a herd using $100 \%$ VO before adopting $75 \%$ AED and $25 \%$ VO,
(3) a herd using 100\% TAI before adopting 100\% AED, and (4) a herd using $100 \%$ TAI before adopting $75 \%$ AED and 25\% TAI. These scenarios are not necessarily representative of today's conventional dairy herds. For example, few herds use a single reproductive management program and many use VO and TAI together. Nonetheless, these scenarios were used to simplify the demonstration, keeping in mind that an end user could input other scenarios they would like to test directly into the online decision support tool.

In situations in which VO was used pre-AED investment, the assumption was that $0.60 \mathrm{~min} / \mathrm{cow}$ per day was required for labor (Galvão et al., 2013), accomplishing a 48.6\% EDR (Dairy Records Management Systems). When TAI was used pre-AED investment, an Ovsynch protocol was assumed for all services (2 doses $\mathrm{GnRH}$ and 1 dose $\mathrm{PGF}_{2 \alpha}$ per service) with a 95\% service rate (Galvão et al., 2013) and a strict 42-d interbreeding interval. In 100\% TAI scenarios, no reinsemination of cows in estrus occurred between TAI services. Each dose of $\mathrm{GnRH}$ and $\mathrm{PGF}_{2 \alpha}$ was estimated at $\$ 2.40$ and $\$ 2.65$, respectively, and labor required for TAI was estimated at $1.00 \mathrm{~min} /$ injection (Galvão et al., 2013). Regardless of reproductive management method (VO, TAI, or AED), labor costs and herd mean CR were held consistent at $\$ 15.00 / \mathrm{h}$ (Galvão et al., 2013) and $36.8 \%$ (Dairy Records Management Systems, Raleigh, NC), respectively.

Automated estrus detection technologies with 2 levels of initial system cost (low: $\$ 5,000$ vs. high: $\$ 10,000$ ), tag price (low: $\$ 50$ vs. high: $\$ 100$ ), and EDR (low: $60 \%$ vs. high: $80 \%$ ) were compared, resulting in 8 AED combinations tested in each of the 4 scenarios. These AED combinations do not necessary represent commercially available technologies or expected results on every farm. Although an assumption was made that AED would always improve EDR compared with VO, that is not always the case. Additionally, achieving an $80 \%$ or greater EDR with AED would likely only occur in rare scenarios. Nonetheless, these examples were chosen to simplify the demonstration, keeping in mind that an end user could input other AED combinations of interest directly into the online decision support tool. Percentage of cows in the herd to receive a tag (100\%), percentage of tags to replace per year (5\%), system maintenance cost per year $(\$ 0)$, and labor required per week $(3.5 \mathrm{~h})$ were held constant in all AED combinations.

Similar investment scenarios were tested in the Wisconsin-Cornell Repro\$ (UW-CURepro\$) online tool located at http://dairymgt.uwex.edu/tools.php. Comparisons between results of that model and the current model are made in the discussion. 


\section{RESULTS AND DISCUSSION}

\section{Objective 1: Cost of Days Open Equations}

The $\mathrm{R}^{2}$ values of the resulting cost of DO models were $0.84,0.81,0.85,0.85$, and 0.87 for parities 1 to 5 , respectively. Using the assumptions in Table 1 and a $50 \%$ EDR, parity-specific total costs of DO per cow between 60 and 300 DIM are shown Figure 1. The points along each line represent the cumulative sum of the daily calculated cost of DO between the end of the VWP and the current DIM. For example, at 100 DIM, a parity-1 cow has a $\$ 5.00$ total cost of DO (approximately $\$ 0.12$ per DO), whereas a parity- 2 cow has a $\$ 25.00$ total cost of DO (approximately $\$ 0.60$ per DO). At 300 DIM, the total cost of days open in all parities falls between $\$ 75$ and $\$ 100$ ( $\$ 0.31$ to $\$ 0.41$ per DO). In general, total cost of DO increases over DIM. However, the pattern of cost per DO changes across DIM. Between the VWP (60 d) and around 250 DIM, the cost per DO is rising at an increasing rate. After that point in parities $2,3,4$, and 5 , the curve begins to flatten, indicating diminishing returns. The reason the cost of DO does not continue to climb at a high rate as DIM increases in late lactation is because the cow is approaching a point of negative returns to investment. At that point, it would be more profitable to cull the cow and replace her rather than keep her. Although the total cost of DO will continue to increase beyond 300 DIM, we expect to see the cost per DO to continue to decrease.
Parity 1 displays a different total cost of DO curve than do the other parities. From the end of the VWP until 100 DIM, total cost of DO is zero, indicating no value in breeding a cow in those scenarios. Additionally, as far into lactation as 300 DIM, the parity-1 curve continues to increase at an increasing rate. Similar to this study, Groenendaal et al. (2004) found the cost of DO to be lower and increase slower in parity 1 . This repeated result has been attributed to increased milk production persistency in parity 1 .

Overall, average cost per DO using US Holstein herd inputs between 60 and 300 DIM across all parities ranged from $\$ 0.00$ in early lactation parity- 1 cows to $\$ 0.56$ in mid-lactation parity- 2 cows. Using the same RPO approach to cost of DO, Groenendaal et al. (2004) found a larger range and, in general, greater costs per DO ( $\$ 0.00$ to $\$ 3.00)$. The main difference between Groenendaal et al. (2004) and this study was the period over which RPO was considered. Groenendaal et al. (2004) calculated RPO monthly, whereas this study used daily RPO. Timing of costs and revenues are critical to RPO calculations and likely contributed to a portion of the differences found between the 2 studies. Other previous estimates of cost per DO (unadjusted for inflation) were $\$ 1.37$ (Meadows et al., 2005), $\$ 3.19$ to $\$ 5.41$ (De Vries, 2006), and $-\$ 1.54$ to $\$ 2.78$ (Liang, 2013). The results from the current study appear to be more conservative than those from previous studies. These results only reflect the scenario that was simu-

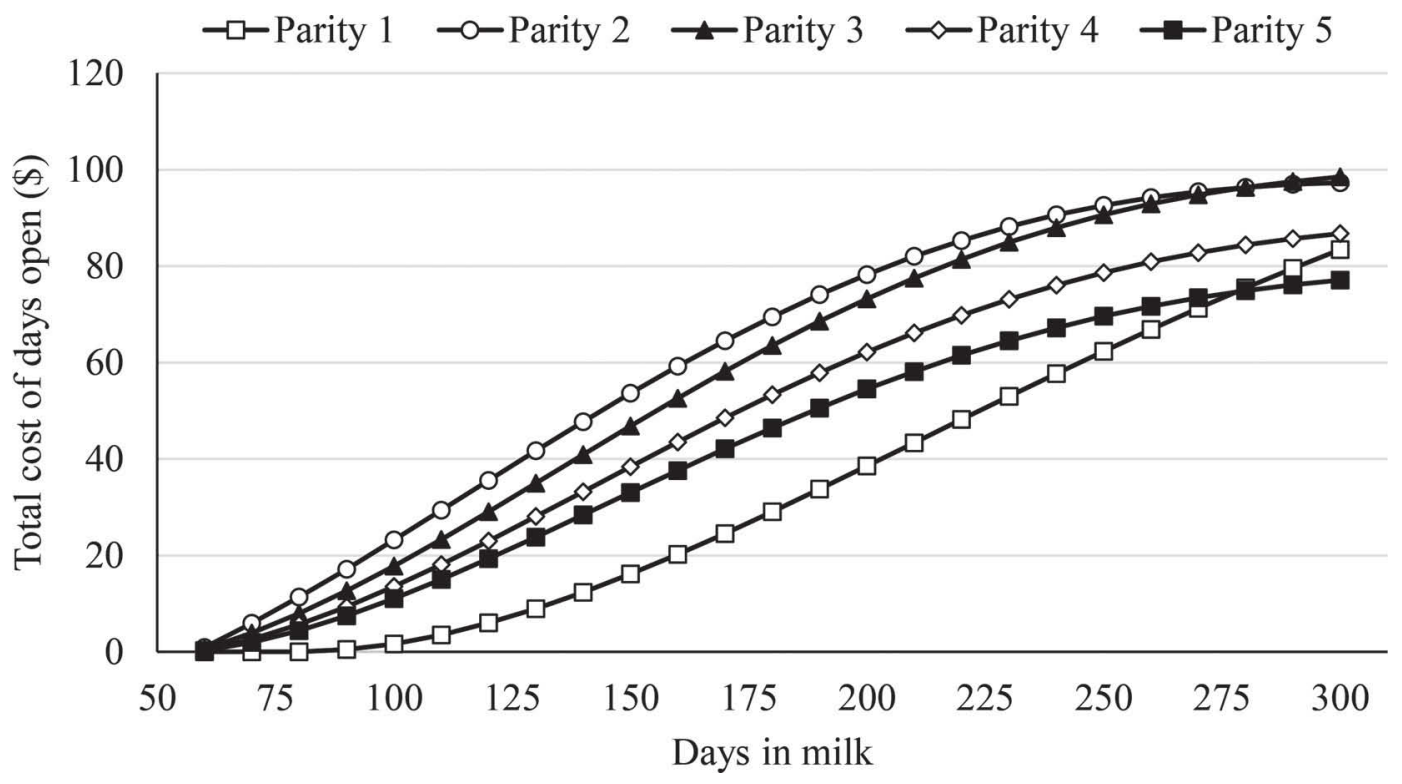

Figure 1. Parity-specific total cost of days open per cow across days in milk estimated using regression equations and assumptions from Table 1. Estrus detection rate was set at $50 \%$ in all scenarios. 
lated and may not be appropriate for generalization to all individual farm conditions.

The full regression equations developed to estimate parity-specific cost per DO are available in an online spreadsheet and as an online decision support tool at https://afs.ca.uky.edu/dairy/decision-tools/CostDaysOpen. These tools can replace stochastic simulation models, reducing time required to estimate the costs associated with reproductive management changes.

\section{Objective 2: Investment Analysis Demonstration}

Net present value determines the profitability of an investment by considering the differences between returns and costs, including the time value of money (Butler, 1996). When NPV is less than zero, an investment is not profitable. A NPV equal to or greater than zero implies a favorable investment. Net present value per cow per year for the 4 investment scenarios $(100 \%$ $\mathrm{VO}$ to $100 \%$ AED, $100 \% \mathrm{VO}$ to $75 \%$ AED and $25 \%$ VO, $100 \%$ TAI to $100 \%$ AED, and $100 \%$ TAI to $75 \%$ AED and 25\% TAI), considering varying AED initial system cost, tag price, and EDR combinations over a 7-yr period are shown in Table 2. Within each scenario, the NPV was always least in the $\$ 10,000$ initial system cost, $\$ 100$ tag price, and $60 \%$ AED EDR combination and greatest in the $\$ 5,000$ initial system cost, $\$ 50$ tag price, and $80 \%$ AED EDR combination. This outcome was expected because of the combined extremes of total AED investment costs and EDR.

Of the 3 varying factors analyzed in this example, tag price ( $\$ 50$ vs. $\$ 100$ ) affected NPV the most, followed by the initial system cost ( $\$ 10,000$ vs. $\$ 5,000)$, and finally the AED EDR (60 vs. $80 \%$ ). Variable costs (tag price) being more influential than fixed costs (initial system cost) shows how herd size and the number of tags purchased will influence investment results. For this investment analysis demonstration, an assumption of 1 tag per cow was used. Alternatively, a herd could transfer tags between cows following pregnancy confirmation, substantially decreasing this cost.

Although variation in only these 3 AED factors was considered in this study, the effect of variation in other input values (length of investment, herd size, preinvestment EDR, etc.) should also be acknowledged. For example, Giordano (2015) studied how varying

Table 2. Change in days open, change in reproductive cull percentage, net present value (NPV) per cow per year ${ }^{1}$ (over a 7 -yr period), and payback period ${ }^{1}$ associated with switching from either visual observation ${ }^{2}$ (VO) or timed $\mathrm{AI}^{3}$ (TAI) as a reproductive management method to either automated estrus detection (AED) or a combination of AED and VO or TAI

\begin{tabular}{|c|c|c|c|c|c|c|c|c|}
\hline \multirow[b]{2}{*}{ Investment scenario } & \multicolumn{8}{|c|}{ AED technology combination ${ }^{4}$} \\
\hline & $\begin{array}{c}\$ 5,000 \\
\$ 50 \\
60 \%\end{array}$ & $\begin{array}{c}\$ 5,000 \\
\$ 100 \\
60 \%\end{array}$ & $\begin{array}{c}\$ 10,000 \\
\$ 50 \\
60 \%\end{array}$ & $\begin{array}{c}\$ 10,000 \\
\$ 100 \\
60 \%\end{array}$ & $\begin{array}{c}\$ 5,000 \\
\$ 50 \\
80 \%\end{array}$ & $\begin{array}{c}\$ 5,000 \\
\$ 100 \\
80 \%\end{array}$ & $\begin{array}{c}\$ 10,000 \\
\$ 50 \\
80 \%\end{array}$ & $\begin{array}{c}\$ 10,000 \\
\$ 100 \\
80 \%\end{array}$ \\
\hline \multicolumn{9}{|l|}{ VO to $100 \%$ AED } \\
\hline Change in days open $(d)$ & -15.3 & -15.3 & -15.3 & -15.3 & -35.3 & -35.3 & -35.3 & -35.3 \\
\hline Percentage change in reproductive culls & -43.8 & -43.8 & -43.8 & -43.8 & -81.2 & -81.2 & -81.2 & -81.2 \\
\hline \multicolumn{9}{|l|}{$\mathrm{VO}$ to $75 \%$ AED and $25 \% \mathrm{VO}$} \\
\hline Change in days open $(\mathrm{d})$ & -12.3 & -12.3 & -12.3 & -12.3 & -28.3 & -28.3 & -28.3 & -28.3 \\
\hline Percentage change in reproductive culls & -34.9 & -34.9 & -34.9 & -34.9 & -70.7 & -70.7 & -70.7 & -70.7 \\
\hline NPV/cow per year $(\$)$ & 15.4 & 8.6 & 13.2 & 6.4 & 17.0 & 10.3 & 14.8 & 8.1 \\
\hline Payback period (yr) & 1.9 & 3.7 & 2.5 & 4.5 & 1.8 & 3.4 & 2.4 & 4.1 \\
\hline \multicolumn{9}{|l|}{ TAI to $100 \%$ AED } \\
\hline Change in days open (d) & 11.4 & 11.4 & 11.4 & 11.4 & -8.6 & -8.6 & -8.6 & -8.6 \\
\hline Percentage change in reproductive culls & -52.0 & -52.0 & -52.0 & -52.0 & -79.4 & -79.4 & -79.4 & -79.4 \\
\hline NPV/cow per year $(\$)$ & 6.3 & -0.5 & 4.1 & -2.7 & 7.9 & 1.2 & 5.7 & -1.0 \\
\hline Payback period (yr) & 3.4 & 7.4 & 4.5 & 9.2 & 3.0 & 6.3 & 4.0 & 7.7 \\
\hline
\end{tabular}


life expectancy of an AED system affected investment break-even point, noting that an AED system must last for at least 5 yr to be profitable.

$\boldsymbol{V O}$ vs. $\boldsymbol{A} \boldsymbol{E D}$. In this investment scenario, payback period ranged from 1.6 to 3.8 yr (Table 2). Regardless of AED initial system cost, tag price, and EDR, NPV was always positive and indicated a positive investment situation (Table 2). Similarly, the UW-CURepro\$ tool also predicted positive benefits using any combination in this investment scenario with an estimated increase in profit per cow per year ranging from $\$ 55.80$ to $\$ 94.30$. The 2 factors contributing to the observed positive NPV were the reduced variable costs associated with reproductive management and the improved EDR. Labor was the only variable cost associated with VO and was estimated at $\$ 54.60$ per cow per year, using the assumption of $0.60 \mathrm{~min}$ required per cow per day (Galvão et al., 2013). Variable costs associated with the AED system included labor and tag replacement costs, totaled $\$ 10.95$ and $\$ 13.45$ per cow per year for $\$ 50$ and $\$ 100$ tag prices, respectively. The resulting variable cost savings associated with AED investment were $\$ 41.15$ to $\$ 43.65$ per cow per year. Reduced labor costs or time committed to VO could result in a situation where investing in AED would be unprofitable, if VO EDR were not compromised.

In the pre-investment scenario, when only $\mathrm{VO}$ with a $48.6 \%$ EDR was used, DO was $153 \mathrm{~d}$ and reproductive cull rate was $11.46 \%$. The improved reproductive performance using AED resulted in DO of 138 or 118 and a reproductive cull rate of 6.44 or $2.16 \%$ when AED EDR was 60 or $80 \%$, respectively. Rutten et al. (2014) simulated similar changes as an average Dutch dairy transitioned from $\mathrm{VO}(\mathrm{EDR}=50 \%)$ to AED $(\mathrm{EDR}=80 \%)$, finding a 16 -d reduction in DO. Improving EDR associated with VO would reduce NPV and could eventually lead to an unprofitable AED investment situation, depending on individual herd circumstances.

VO vs. $75 \% A E D$ and $25 \%$ VO. In this investment scenario, payback period ranged from 1.8 to $4.5 \mathrm{yr}$ (Table 2). Compared with the previous scenario, EDR did not increased as greatly, nor did labor cost decrease as much, explaining the increased payback period and reduced NPV (Table 2). However, NPV remained positive for all combinations of initial system cost, tag price, and AED EDR. The UW-CURepro\$ tool profit per cow per year results also decreased compared with the first scenario ( $\$ 51.70$ to $\$ 79.00$ ), but remained profitable.

By combining AED and VO, reproductive performance improved compared with VO alone, but not to the same extent as when using AED alone because of the low VO EDR. Days open was reduced to $125 \mathrm{~d}$ and reproductive cull rate was reduced to $3.36 \%$ in combi- nations using 60\% AED EDR. Days open was reduced to $141 \mathrm{~d}$ and reproductive cull rate was reduced to $7.46 \%$ in combinations using $80 \%$ AED EDR.

$\boldsymbol{T A I}$ vs. $\boldsymbol{A} \boldsymbol{E} \boldsymbol{D}$. In this investment scenario, payback period ranged from 3.3 to over 10 yr (Table 2). A positive NPV was only observed in the 4 combinations using a $\$ 50$ tag price. If a $10-y r$ investment period had been used, all but one combination ( $\$ 10,000$ initial investment cost, $\$ 100$ tag price, and $60 \%$ EDR) would have resulted in a positive NPV. This outcome highlights the importance of defining a correct expected lifespan of the AED system for accurate investment analysis. In comparison, the UW-CURepro\$ tool found 2 combinations to be good investments in this investment scenario: $\$ 5,000$ initial cost, $\$ 50$ tag price, and $80 \%$ EDR, and $\$ 10,000$ initial cost, $\$ 50$ tag price, and $80 \%$ EDR. Profit per cow per year using the UW-CURepro\$ tool ranged from $-\$ 38.9$ to $\$ 4.4$.

Reproductive performance was improved when AED EDR was 80\% (DO decreased from 127 to $118 \mathrm{~d}$ and reproductive cull rate decreased from 8.44 to $2.16 \%$ ). Reproductive performance as measured by DO was reduced when AED EDR was 60\% (DO increased from 127 to $138 \mathrm{~d}$ ), but improved if measured by reproductive cull rate (decreased from 8.44 to $6.44 \%$ ). In this case, the shortened service interval when using AED (21 vs. $42 \mathrm{~d}$ when using TAI) provided cows more breeding opportunities before being designated as a reproductive cull. However, this result was offset by the high service rate associated with TAI $(95 \%)$, resulting in a longer DO. An additional benefit of TAI is a shorter time to first service.

Although reproductive performance improvements similar to the $80 \%$ AED EDR combinations were seen in the first investment scenario (VO to AED), variable costs were not reduced as much in this scenario, resulting in the reduced NPV results. Variable costs associated with TAI were $\$ 12.68 /$ cow per year. When switching from TAI to AED, variable costs increased $\$ 0.77 /$ cow per year when using AED with a $\$ 100$ tag price and decreased $\$ 1.73 /$ cow per year when using AED with a $\$ 50$ tag price.

TAI vs. $75 \%$ AED and $25 \%$ TAI. In this investment scenario, payback period ranged from 3.0 to 9.2 yr (Table 2). A positive NPV occurred in all combinations that included a $\$ 50$ tag price plus one combination that included a $\$ 100$ tag price $(\$ 5,000$ initial cost, $\$ 100$ tag price, $80 \%$ EDR). Again, this result highlights the importance of low initial cost as a major influencing factor in the profitability of AED investment. The UWCURepro\$ tool did not allow a user to simultaneously use both TAI and AED independent of each other. Therefore, no comparisons can be made between that tool and this one for this investment scenario. 
The combination of TAI and AED with an $80 \%$ EDR produced the best reproductive performance results of any combination in any scenario. In the pre-investment scenario, when only TAI with a $95.0 \%$ service rate was used, DO was $127 \mathrm{~d}$ and reproductive cull rate was 8.44\%. When combined with AED achieving an $80 \%$ EDR, DO decreased to $115 \mathrm{~d}$ and the reproductive cull percentage decreased to $1.74 \%$. Regardless, the cost associated with using both reproductive management systems simultaneously was not profitable in every tested combination.

Both TAI scenarios produced some negative NPV results, indicating poor investment situations. However, those results assume near-perfect TAI compliance (95\%), which is not always the case. Compliance with TAI protocols is often overlooked, even though it can have a greater negative effect on reproductive performance than poor accuracy of estrus detection (Galvão et al., 2013). By assuming high compliance, our investment analysis demonstration may have favored TAI. However, an assumption was made that TAI cows would not be rebred until after pregnancy diagnosis, regardless of observed estrus activity. In practice, rebreeding TAI cows observed in estrus before pregnancy diagnosis is common. Additionally, some TAI protocols are designed specifically to decrease the breeding interval. Therefore, our assumption of a strict 42 -d breeding interval when using TAI may have favored the AED investment.

\section{Further Considerations}

The most accurate decision-making model would be one that considered all interactions occurring on a dairy farm. Alternatively, a partial budget model, such as the one presented in this study, has the benefit of using simple inputs and calculations to quickly produce an estimated response to a management change. However, the results rely heavily on assumptions made by the user and must be interpreted carefully. The output represents the relative expected consequences rather than exact numbers. Encouragingly, results from this study and values found using a similar tool (UW-CURepro\$) produced comparable results, especially in the investment scenarios using VO. However, the current model seems to be more conservative in economic estimates.

The suggested use of this decision support tool would be as one of the first steps in an investment consideration. Upon positive results using this partial budget, more advanced tools and further budgeting strategies should be explored. Making decisions based on the results of this tool alone could result in costly mistakes. Specifically, some factors that were not accounted for in this model include the change in herd structure resulting from changes in reproductive performance (e.g., increased heifer calf inventory, increased herd age, and lifetime net returns), additional potential benefits from the AED system (e.g., disease monitoring, calving detection), the use of AED technologies on breeding age heifers, and the effect of AED on the quality of a dairy producer's life. Future users are encouraged to test multiple scenarios in the decision support tool to evaluate expected results in a variety of herd-specific situations.

\section{ACKNOWLEDGMENTS}

The authors thank Di Liang, a PhD student at the University of Wisconsin, Madison, for her assistance in developing the model for cost of DO.

\section{REFERENCES}

Bewley, J., M. Boehlje, A. W. Gray, H. Hogeveen, S. Kenyon, S. Eicher, and M. Schutz. 2010. Stochastic simulation using @Risk for dairy business investment decisions. Agr. Financ. Rev. 70:97-125.

Boehlje, M., and C. Ehmke. 2005. Capital Investment Analysis and Project Assessment. Purdue Extension Agricultural Innovation and Commercialization Center, West Lafayette, IN.

Borchers, M. R., and J. M. Bewley. 2015. An assessment of producer precision dairy farming technology use, prepurchase considerations, and usefulness. J. Dairy Sci. 98:4198-4205.

Britt, J. H. 1985. Enhanced reproduction and its economic implications. J. Dairy Sci. 68:1585-1592.

Butler, L. D. 1996. Understanding Internal Rate of Return and Net Present Value. USDA, Washington, D.C.

De Vries, A. 2006. Determinants of the cost of days open in dairy cattle. Page 1114 in Proceedings of the 11th Symposium of the International Society for Veterinary Epidemiology and Economics. International Society for Veterinary Epidemiology and Economics, Cairns, Australia.

Dhuyvetter, K. C., T. L. Kastens, M. Overton, and J. Smith. 2007. Cow culling decisions: Costs or economic opportunity? Pages 173187 in Proc. Western Dairy Management Conference, Reno, NV. Oregon State University, Corvallis.

Fricke, P. M., J. O. Giordano, A. Valenza, G. Lopes Jr., M. C. Amundson, and P. D. Carvalho. 2014. Reproductive performance of lactating dairy cows managed for first service using timed artificial insemination with or without detection of estrus using an activitymonitoring system. J. Dairy Sci. 97:2771-2781.

Galvão, K. N., P. Federico, A. De Vries, and G. M. Schuenemann. 2013. Economic comparison of reproductive programs for dairy herds using estrus detection, timed artificial insemination, or a combination. J. Dairy Sci. 96:2681-2693.

Giordano, J. O. 2015. Use of technologies in reproductive management: Economics of automated activity monitoring systems for detection of estrus. Pages 51-66 in Proc. Western Dairy Management Conference, Reno, NV. Dairy Conferences LLC, Manhattan, KS.

Giordano, J. O., P. M. Fricke, M. C. Wiltbank, and V. E. Cabrera. 2011. An economic decision-making support system for selection of reproductive management programs on dairy farms. J. Dairy Sci. 94:6216-6232.

Giordano, J. O., A. S. Kalantari, P. M. Fricke, M. C. Wiltbank, and V. E. Cabrera. 2012. A daily herd Markov-chain model to study the reproductive and economic impact of reproductive programs combining timed artificial insemination and estrus detection. J. Dairy Sci. 95:5442-5460. 
Groenendaal, H., D. Galligan, and H. Mulder. 2004. An economic spreadsheet model to determine optimal breeding and replacement decisions for dairy cattle. J. Dairy Sci. 87:2146-2157.

Holmann, F. J., R. W. Blake, and C. R. Shumway. 1987. Economic evaluation of fourteen methods of estrous detection. J. Dairy Sci. 70:186-194.

Hyde, J., and P. Engel. 2002. Investing in a robotic milking system: A Monte Carlo simulation analysis. J. Dairy Sci. 85:2207-2214.

Liang, D. 2013. Estimating the economic losses from diseases and extended days open with a farm-level stochastic model. MS Thesis. Animal and Food Sciences, University of Kentucky, Lexington.

Meadows, C., P. Rajala-Schultz, and G. Frazer. 2005. A spreadsheetbased model demonstrating the nonuniform economic effects of varying reproductive performance in Ohio dairy herds. J. Dairy Sci. 88:1244-1254.

Olynk, N. J., and C. A. Wolf. 2008. Economic analysis of reproductive management strategies on US commercial dairy farms. J. Dairy Sci. 91:4082-4091.

Olynk, N. J., and C. A. Wolf. 2009. Stochastic economic analysis of dairy cattle artificial insemination reproductive management programs. J. Dairy Sci. 92:1290-1299.
Pecsok, S. R., M. L. McGilliard, and R. L. Nebel. 1994. Conception rates. 1. Derivation and estimates for effects of estrus detection on cow profitability. J. Dairy Sci. 77:3008-3015.

Plaizier, J. C., G. J. King, J. C. Dekkers, and K. Lissemore. 1997. Estimation of economic values of indices for reproductive performance in dairy herds using computer simulation. J. Dairy Sci. 80:2775-2783.

Russell, R. A., and J. M. Bewley. 2013. Characterization of Kentucky dairy producer decision-making behavior. J. Dairy Sci. 96:47514758.

Rutten, C. J., W. Steeneveld, C. Inchaisri, and H. Hogeveen. 2014. An ex ante analysis on the use of activity meters for automated estrus detection: To invest or not to invest? J. Dairy Sci. 97:6869-6887.

Stevenson, J. S., S. L. Hill, R. L. Nebel, and J. M. DeJarnette. 2014 Ovulation timing and conception risk after automated activity monitoring in lactating dairy cows. J. Dairy Sci. 97:4296-4308. 